\title{
Uncovering the Experiences of Engaging Indigenous Knowledges in Colonial Structures of Schooling and Research
}

\author{
Mairi McDermott, Jennifer MacDonald, Jennifer Markides, Mike Holden
}

\begin{abstract}
In response to the Truth and Reconciliation Calls to Action (TRC, 2015), a school board teamed with university educators and educational partners to generate a professional learning series to support educators' engagement with Indigenous knowledges. A research team that assembled two years later interviewed the learning series participants to explore how educators were navigating Indigenous knowledge within a Eurocentric school system. This research acknowledges the challenges of doing this work within shifting institutional policies and initiatives, the wider politics of Indigenous and non-Indigenous relations, building intercultural understandings and community partnerships, and negotiating epistemological difference. The researchers - including Indigenous and non-Indigenous peoples - echoed resonances with the participants that occurred throughout the data collection process and often spoke about the parallel paths of research and schooling - both historically used as tools of colonization and now having a role in decolonization. To disrupt colonial propensities, we share our reflections as researchers, specifically around complexities and tensions of engaging Indigenous knowledges throughout our research processes concerning the participants' experiences. By sharing the tensions and (un)learning that emerged on these parallel paths, we honour diverse entry-points and experiences to animate how trans-systemic knowledge building might ensue.
\end{abstract}

KeYWords Indigenous education, Eurocentrism, trans-systemic knowledges

\section{Into the Beyond-Space}

Eurocentrism is the view that sees Europe [...] as the world's center of gravity, as ontological 'reality' to the rest of the world's shadow, as the originary fountain from which all things flow.... [It is] an ideology which has long entered the bloodstream of the dominant discourses, the educational systems and the media of most countries. (Shohat and Stam, 2009, p. 137, emphasis added)

To understand why Indigenous knowledge was ignored or marginalized in the colonial educational curricula was first to unravel Eurocentrism, something that each of us, despite the school we attended, have been marinated in. (Battiste, 2013b, p. 6, emphasis added) 
If Eurocentrism circulates through the discursive bloodstream of society, and if we are in a time when more people are acknowledging how we have all been marinated in the ravages of this single truth, how do we respond to the Truth and Reconciliation Calls to Action (TRC, 2015)? How might we shift — to think, relate, and engage — beyond the logics of Eurocentrism? Indeed, this is our way of thinking about the call for a trans-systemic approach: "that is, reaching beyond the two distinct systems of knowledge [and] [b]eyond suggesting that neither Indigenous knowledge nor Eurocentric knowledge systems can be the sole arbiter of the work involved" (Battiste, 2013a, p. 103). As a diverse group of researchers, three non-Indigenous and one who identifies as Métis, we each have various relationships to Indigenous and nonEurocentric ways of knowing and being in the world. We realized early on that we must push ourselves into the beyond in our approach to the research discussed in this paper. The question of how to do so emerged through time.

The purpose of assembling our thoughts, processes, contradictions, and hesitancies, as well as our collective and individual perspectives, is to invite readers to join in seeking space for trans-systemic knowledges. We hope to enact decolonial relations on different terms than those offered by remaining in the Eurocentric marinade. As we navigate schooling and research institutions, we draw from a research project interested in how educators are taking up a school board response to the Truth and Reconciliation Calls to Action (TRC, 2015). We traverse this terrain alongside our interview participants and consciously strive to better understand the ways Eurocentric knowledge continues to work on us and how we might open spaces for Indigenous ways of knowing in our teaching and research practices.

In what follows, we start navigating the terrain by discussing the broader context of the research. This leads into a discussion of the different ways we felt compelled to write about the research's unfolding process (or methods) in relation to trans-systemic work. The first part of the paper was written in a collective voice as we describe the original plan. As we continue to spiral out (and perhaps in) from that starting point, each of us provided an individual reading of the data to animate four ideas that resonated with each of us:

(1) emotional connections and becoming human (Jennifer MacDonald);

(2) competing pressures, tensions, responsibilities, and pedagogies (Jennifer Markides);

(3) confronting truths, narratives, and silences (Mike Holden); and

(4) knowledge production, privilege, and solidarity (Mairi McDermott).

We conclude by spiraling back and sharing our insights for reaching and dwelling in the potentials of the trans-systemic, of space beyond.

\section{Part I}

\section{Framing the Initial Research}

In response to the Truth and Reconciliation Calls to Action (TRC, 2015), a school board in Alberta worked in partnership with a team of university educators to generate a professional learning series to support educators' engagement with Indigenous knowledges. The research team assembled two years later to understand how the participating educators might have taken up their learning within their practice. Initially framed as a case study, the research 
was bounded by the educators' identities, who were recruited based on participation in the professional learning series. We assumed a certain level of interest among these educators due to their active pursuit of professional development around ways to incorporate what Alberta Education (2018) calls "Foundational Knowledge about First Nation, Métis, and Inuit"1 (p. 6).

In response to the Truth and Reconciliation Commission Report (2015), we noted a shift in the discussions around and approaches to Indigenous roles in the school board where our participants work. Until this time, Indigenous learning leader roles were assigned to specific schools and focused on supporting individual students who self-identified as Indigenous. The Calls to Action, alongside the development of two Alberta Education policies - the Teaching Quality Standard (TQS) and Leadership Quality Standard (LQS) (Alberta Education, 2019a, 2019b) - marked a shift in the focus of work for educators and education in Canada. Namely, in Alberta, all teachers are asked to "develop and apply foundational knowledge about First Nations, Métis and Inuit for the benefit of all students" (Alberta Education, 2019b, p. 5) and school leaders to "support the school community in acquiring and applying foundational knowledge about First Nations, Métis and Inuit for the benefit of all students" (Alberta Education, 2019a, p. 6). To address knowledge and experience gaps of teaching Indigenous topics and prepare for the implementation of the Quality Standards (in effect as of September 2019), the school board involved in this study created new centralized roles for Indigenous Education to support all schools and students.

As a research team made up of both Indigenous and non-Indigenous scholars coming from diverse entry points to the topic, we engaged in parallel paths alongside the participants, attending to our projects of decolonization and relationality (Donald, 2009, 2016; Kovach, 2009). Each of us were drawn to the research project because we believe in the necessity and possibilities of decolonizing our minds, relations, institutions, and societies (Battiste, 2013b; Patel, 2016a; wa Thiong'o, 1986). The impossibility of some straightforward, linear progressive "answer" or Truth became evermore apparent along the way. The geopolitics of knowledge (Mignolo, 2002; Sandoval, 2000; Wynter, 2003), the relationship between knowledge and social identities, or the pedagogical questions of who can say what, in what ways, to whom, when, and under what conditions, made universalizing the experiences impossible. So, we began to ask ourselves, what can our research do? Through time we realized that it is our individual and collective journeys through the quagmire - as sociopolitically positioned and considering our relationships to knowledge regimes - that echoed in the interviews. In other words, the research became as much a site of negotiating our positions on our learning paths as it was about the participants' practices.

1 This is the language used in Alberta Education's Teaching Quality Standard, a set of competencies that teachers in Alberta are expected to reach towards in their ongoing professional learning and practices. In Canada, the terms First Nations, Métis, and Inuit (FNMI) are sometimes used to refer to Indigenous peoples from different communities. In this paper, we include these terms in reference to policy documents; however, we otherwise use the term "Indigenous" to honour the diverse cultures, knowledges, and histories of Indigenous peoples. 
We assembled as a research team in the fall of 2018. One aspect of our research towards the beyond-space of trans-systemic knowledges materialized at the beginning of our collaboration. Indigenous methodologies are often called upon when working with Indigenous peoples (Smith, 2012). Yet, we cautiously believed that thinking-being-doing research shaped by Indigenous approaches could be repositioned as a significant interruption to how research is conceptualized in the dominant Eurocentric articulations. We reflected that the investigation might involve Indigenous peoples, yet we knew that most of our participants would be non-Indigenous.

Siksika Elder Clarence Wolfleg honoured us by joining our grounding meeting before the research began. Elder Wolfleg's presence and engagement immediately influenced how we paused in our research and returned to lessons in different ways, opening a portal to the transsystemic. Elder Wolfleg reminded us that this is the first generation of educators being formally asked to weave Indigenous knowledge into our teaching practices; relatedly, we have to learn to crawl before we can walk. In other words, we are all amid a continuous learning process, which is necessarily a transformative and challenging process. We need to slow down and first disentangle Eurocentrism from the discursive bloodstream to allow Indigenous lifeforce into our worlds and relations (Graveline, 1998; Hooks, 1994; Patel, 2016b). The longer something has been marinated, the harder it becomes to distinguish the individual ingredients. We must be gentle yet firm and intentional in our learning and knowledge production, something which the pressures of finding immediate solutions and answers in conventional schooling and education do not always support.

As the research proceeded, we noticed that institutional policies and initiatives are just one layer of the response to Truth and Reconciliation (2015); the necessary and challenging work would involve navigating the wider politics of relations between Indigenous and nonIndigenous peoples and groups, building intercultural understandings and communities, and negotiating epistemological differences. We observe inherent tensions play out (Kapyrka \& Dockstator, 2012) as many people, ourselves included, feel lost when seeking how to learn about Indigenous epistemologies, histories, pedagogies, and protocols; i.e., we don't know where to start, whom or how to ask, and frequently fear making mistakes (Dei \& McDermott, 2019; MacDonald \& Markides, 2018, 2019). These awkward moments, however, can provide the learning that is necessary to move forward differently. Donald et al., (2012) suggest that educators use an ethical relational approach to navigate conflicting research, curriculum, and culture expertise, which implies that truth and reconciliation journeys are profoundly personal and dynamic.

\section{Mapping the Process: Methods and Data Sources}

In this section, we discuss our approach toward negotiating Eurocentric and Indigenous ontoepistemologies. In particular, as we work through our struggles and agreements, we want to highlight the historical and ongoing colonial relations of conventional schooling and research uncovering the assumptions underpinning the way we "do school/research" (Battiste, 2013a/b; McDermott, 2020; Patel, 2015; Smith, 2012). We make our work a site of vulnerability to show how we moved within and between two processes influencing the research: (1) a linear, 
planned approach to research guided by the Western Eurocentric regime; and (2) the embodied, relational, and reflexive approach that emerged through time and dialogue about our collective unease with the first approach and what we felt was limiting our ability to ethically honour the complexity of the topic.

\section{Eurocentric, linear planning: The language of measurable outcomes and verifiable truth-claims}

As mentioned, the initial research goal was to investigate what happened during the professional learning series and what has resulted in the school system. Three of the 14 participants who were interviewed were part of the professional learning series planning and implementation team from two partner institutions, while 11 participated in their roles as teachers, principals, assistant principals, program facilitators, and learning leaders within the school board. Four participants identified as having Indigenous heritage. Figure 1 illustrates the underlying process and assumptions about knowledge built into this approach of professional learning.
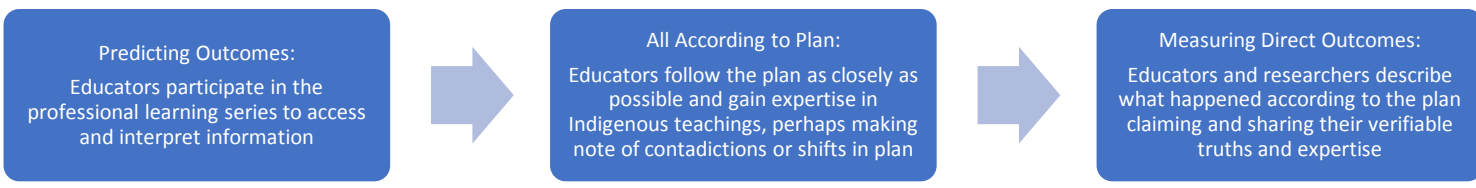

Figure 1. The Eurocentric Linear Plan for Learning and Research

We can reflect now on how our initial process followed a similar logic: researchers engage with interview participants, researchers gain knowledge about participants' experience, researchers share expertise with the community. To transform the orality of interviews into the superior (within the Eurocentric imagination) form of written text, interviews were audiorecorded and transcribed. This allowed the first level of analysis to start at different times for different research team members. The interviewers and transcribers were encouraged to keep a journal with notes about their ponderings and reflections about each interview and what was said and felt. Once all of the transcripts were complete, they were sent back to the participants to check with the invitation to make additions, changes, or deletions. Four of the 14 participants made changes or clarified details in their transcripts. After this process, the next phase of analysis had members of the research team individually read through all the transcripts, focusing on in vivo coding (Miles et al., 2014), wherein we attuned ourselves to what was said and what stories were striking us as meaningful. We then came together to discuss our initial, individual sense of the data, hone the themes that spoke to all of us, and reach consensus about the data's meanings.

\section{Process-driven, spiraling, and emergence of learning and research.}

We found ourselves being able to frame the above description of methods and data sources with relative ease. Why? Because this is the way we are taught and trained to do research. It provides a certain level of comfort and "knowability" that is recognized by us as research and is recognizable to others as legitimate. However "easy" it was, it never felt right. It seemed to miss 
the most compelling aspects of the work for us. It contradicted our emerging premise that we are not seeking an additive model wherein school knowledge and research structures are left intact with minor sprinklings of Indigenous ways of knowing and ways of being periodically introduced.

As we gained confidence in our individual and collective positions on these uneven terrains of recognizable research, we came to reconsider and differently assess what we did in the research. What follows, then, is our approach to embody how we were individually drawn to divergent and convergent stories interpreted within the data. Yes, the data were collected in the way we described above; and perhaps in our first attempt to collectively analyze the data, we defaulted back to the habit of coding the transcripts for themes upon which we agreed. To resist the pull towards coding until saturation and consensus (e.g., singular reading), in our first analysis meeting, we started by asking, "what stories stood out or resonated with you?" When we shared those stories, we then attempted to categorize the stories to indicate our initial findings. Again, this did not feel right, so we had to be our own critical friends.

We took a step back and, after a prompt by one of the team members, we each wrote down our relationship to the research. Why did we decide to participate in the project, and what did we desire for and from the work? This exercise helped us further build our relationships as a team and recognize the different reasons and life experiences that brought us to the research. We each returned to the data after this "aha" moment to listen for the stories that resonated deeply with our purposes for doing the research, which then prompted us to realize that each time we went back to the data-as-story, we were taking away different meanings because along the way we were growing, learning, and needing something else. Much like Indigenous storytelling,

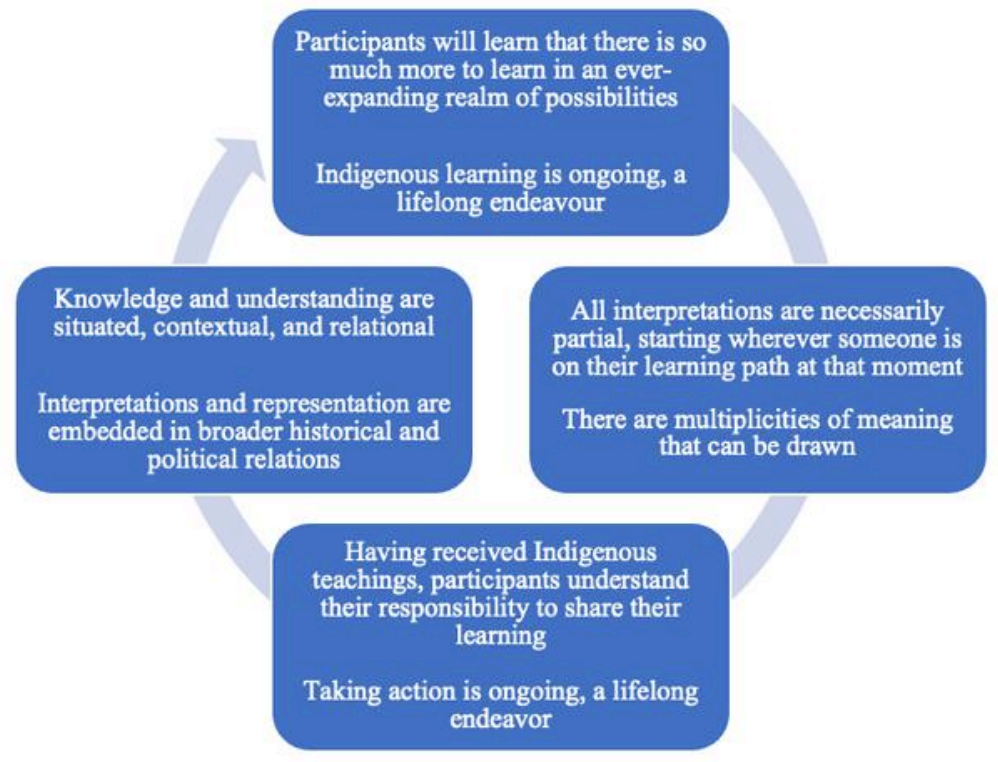

Figure 2. The Process-driven Indigenous Learning (Learning Through Research) 
there is no singular, ultimate, or universal meaning to the story (Archibald, 2008). Like the teaching and learning relations we experienced with Elder Wolfleg, we came to understand how working with data can also let the stories work on us by keeping them alive, local, and situated. Figure 2 illustrates this shift in our thinking about learning and research in an alternative, process-driven framework.

We share in Part 2 how each researcher makes sense of the research at this moment of writing to situate ourselves in relation to the participants' experiences and the social identities and experiences that shape our interpretations of what mattered in the research.

\section{Part 2}

\section{Embodying Trans-Systemic Sense-Making By Weaving Participants' and Researchers' Stories}

To embody the sensibility that stories continually work on us depending on where we are socially, spiritually, conscientiously, and physically situated, we play with a contextualized and layered interpretation of the data's stories. Each researcher positions themselves regarding our individual desires for the research and situatedness on our journeys. In this way, the reader gets a sense of the different ways the data was read concerning who we are and how we attempt to weave Indigenous and Eurocentric knowledge regimes.

\section{Emotional Connections and Becoming Human (Jennifer MacDonald)}

When I returned to the interviews time and again, I was struck that sentiments about this work were intensely personal and emotional across the diverse participants. Understandably, with topics such as intergenerational trauma, abuse, and a general need to shift historical consciousness to address racism, that complicated and challenging responses, ideas, and opinions would emerge. Crying, laughter, and sentiments of frustration, exhaustion, disappointment, hope, confusion, nervousness and excitement, were among the conscious feelings readily apparent to me when reading the transcripts.

As a non-Indigenous person, I am absorbed with the project of expanding my worldview, and I work with care in the field of Indigenous education. The theme of intricate emotional work resonates with my experience. While I have been mentored by different people in Indigenous knowledges and worldviews, I know that I grew up marinating in Eurocentric knowledge, which persists in how I see the world. Releasing myself from the marinade will be a lifelong project. Likewise, I am always cognizant that this shifted focus towards reconciliatory agendas may re-traumatize and burden others who have endured the realities of intergenerational colonial violence. As I worked on myself, I also wanted to bring others like me into the circle to heal the mess that we inherited - how might we limit the Eurocentric contamination of the discursive and social bloodstream from flowing to the next generation?

bell hooks (1994) writes that "there can be, and usually is, some degree of pain involved in giving up old ways of thinking and knowing and learning new approaches" (p. 43). For participants coming to learn different interpretations of Canadian truths, the power of hearing 
personal accounts was striking. For example, Mark ${ }^{2}$ talked about listening to an Elder's story of attending residential school, "I felt like he was the way he spoke, he really, you could see what was happening when you were in there with him. So that was pretty emotional." In turn, these learning moments helped him develop a more critical lens to recognize deeply rooted systemic injustices in his everyday interactions:

I realized we're really insensitive and inaccurate [...] looking at things through a more critical lens in that way, in just everyday interactions that I, you don't know what you don't know. How much I have missed in the past that I'm much more aware of now. I never really thought about how a lot of these people were suffering were there because of policies of our government and then, I think what lit a fire under me is realizing that I work for the same government, I work for the same system that did this harm.

Developing critical sensibility can empower us to recognize our own complacency in the problems and increase knowledge, but this can also lead to confusion and isolation if we don't know what to do with it. For example, when I began noticing knowledge gaps and pointing out imbalances within my institutions, I often felt that I was questioned — from both sides and I had to negotiate a line between resting in the critical and imagining other possibilities. Through this process, I worried that my intentions would be interpreted as disrespectful. As I learned to listen to my gut to discern obligation in Indigenous spaces, I recognized that I often spent too much time second-guessing and not just trusting myself. Making mistakes and stumbling are also part of the learning (Wagamese, 2016). Many of the participants, including Mark, talked about the significance of generating artifacts and giving presentations about the learning series to their colleagues; they spoke about the experience bringing others in and involving them in the work. However, the institutional challenge of regularly changing teams, locations, and continually starting over made it difficult to find traction in the work participants wanted to do after the learning series.

Over the past several years, I was drawn to complicated and uncomfortable positions to work out my responsibilities. Opportunities for humble self-questioning repeatedly surfaced, at times in harsh ways. Once I began recognizing myself as a colonizer, I wanted to learn how to respond respectfully and to enact the choice to do so regularly. The fact that I had a choice, again, was the privilege. Many participants spoke to this felt commitment from the professional learning series, understanding the importance of this work in schools, and were enthusiastic about living it out in their own contexts. However, some spoke to the resistance endured from their colleagues and inner frustrations when others did not understand the significance of the task. Coral spoke to the heaviness and emotional labour of frequent encounters with colleagues who felt that the momentum towards reconciliation was a personal attack on them, and needing to guard herself from the enormity of the task:

2 All names of participants are pseudonyms. 
I deal with people thinking about why so many resources are being put in towards an Indigenous education strategy, into a full-time grad coach, to the attention that is being paid, when they recognize and see that there are many students who could use that additional support. I can only control the conversations that are had with me present. And that took me a long time to create that boundary for myself, to be able to say, like, I can help you unpack as far as I think you are able to in terms of your understanding and expectation of what my role is here.

Like other social justice work, reconciliation initiatives are inherently political and can stir many divisive responses (Sensoy \& DiAngelo, 2012). Other participants spoke to the frustration of continual ignorance and that the people who need to learn the most do not take the time. There needs to be recognition of the why underneath this work, so the quick impulse towards the how does not get lost by the politics.

Ultimately, reconciliation work should strive towards becoming human. I am drawn to Coral, who comments on foundational knowledge: All people already have a foundation. Of course, amid the complexities we all have the answers within us. Learning to slow down, to listen deeply, and articulate the tension is essential work. Paulette Regan (2010) speaks to this, saying, "Connecting head, heart, and spirit in ways that value vulnerability and humility enables us to accept harsh truths and to use our moral imagination in order to reclaim our own humanity" (p. 237). The learning is deeply layered, and I understand it will continue to work on me as long as I am open and resist needing to control the outcome. When I keep that in mind, it becomes more than including or embedding Indigenous knowledge content — or seeing this knowledge as something we can just acquire — but it needs to be lived with, dwelled with, struggled with.

\section{Competing Pressures, Tensions, Responsibilities, and Pedagogies (Jennifer Markides)}

Several examples of competing pressures arose through the interview conversations. Participants remarked that some colleagues were reluctant to teach about Indigenous topics because they believed they did not have any Indigenous students in their classes. These comments highlight a prevailing misconception that Indigenous education is only for Indigenous students (Battiste, 2013a).

Some participants noted that they wanted to take up Indigenous topics but worried it was not their place or that their knowledge was inadequate because they were not Indigenous themselves. Cassidy stated, "I don't have deep, deep understanding of Indigenous cultures because I'm not Indigenous." While this concern often comes from a place of genuine care, it implies that only Indigenous people can teach Indigenous education; it also assumes that Indigenous people - by virtue of being Indigenous — have expertise in Indigenous teachings and knowledges.

Unfortunately, many Indigenous people, myself included, have been raised outside of their home communities due to the systemic violence perpetuated and enacted by programs, 
initiatives, and laws intended to assimilate Indigenous people into the body politic. Many Indigenous people are raised with little connection to their culture. Parents and grandparents choose to "protect" their children from the racism and oppressive systems by not teaching them their language, ceremonies, histories, and practices (Four Arrows, 2008; MacDonald \& Markides, 2019; St. Denis, 2007).

Two of the participants who identified as having Indigenous heritages - Cristina and Kylie - expressed feelings of loss and guilt for not knowing more about their cultures. Cristina recalled, for example, that she was not legally recognized as Indigenous until her mid-twenties, at which time her mother informed her that the government has now changed their policies and you are now status First Nation. ${ }^{3}$ Despite the years spent without her status, Cristina's grandmother had shared teachings with her while being out on the land. They picked berries, set traps, fished, and hunted; as she recalled, "there would always be moose hanging in the basement."

Yet, Cristina expresses sorrow for not being immersed in her culture.

Similarly, Kylie shared her story of [growing] up without culture. Her mother was nonIndigenous, and her father was Indigenous. Kylie noted that her father's mother had passed away during childbirth and, therefore, she was raised in the absence of his mother's teachings, as cultural knowledge would have been passed down from the matriarch. Concerning the learning series, Kylie said, "I remember feeling a really strange combination of like, anxiety, and pride" as she learned alongside the Elders and Knowledge Keepers. Despite the teachings she received, she remarked, "It's just crazy. I still feel very inadequate."

As often happens when I am listening to the experiences of Indigenous people raised without traditional teachings, ceremonies, and structures, I can relate to the feelings of guilt and inadequacy - an Indigenous imposter syndrome. The influences of colonization doubly harm Indigenous people living under these circumstances: first, we suffer from the absence or loss of cultural connections, experiences, and teachings; and second, we struggle with never feeling Indigenous enough as we try to (re)connect, (re)claim, and (re)inhabit our whole selves. Kylie says, "I still carry with me quite a bit of shame for not taking steps earlier, and not knowing more."

I could also relate to Kylie's inner conflict as she learned from the Blackfoot Elders, who led parts of the learning series. She explained, "I know more about Blackfoot than I know about my own [community]." Fortunately, Kylie had a dear friend who reminded her that "our Elders are sacred no matter what [and] our Elders are important no matter where they're from." Hearing this was important because, as she says, "It gave me permission to still seek out support here."

As a participant in the learning series and leader of Indigenous professional learning, Laura described a tension between wanting to provide spaces for participants to learn from Elders but not wanting them to think that all Indigenous teachings need to come from Elders. I believe this point may be ripe for further research and commentary. In the way of cooperative binaries described by Barbara Mann (2003), Elders' teaching and the teachings of others do not need to

3 In 1985, Bill C-31 was passed to amend the Indian Act to remove remaining enfranchisement clauses (Government of Canada, 2020). 
be held in opposition; instead, both may be privileged simultaneously. Educators' roles in the sense of other teachings extend beyond Indigenous and non-Indigenous to include the morethan-human world (Abram, 1996; Sheridan \& Longboat, 2006).

From participants who were wary to begin the learning journey in Indigenous education to those who were already engaging in Indigenous circles and learning from Elders, all participants shared a common desire/need for ongoing learning opportunities for themselves. This common sentiment illustrates that the more you learn in Indigenous education, the more aware you become of how little you know. Being in this kind of weak position stands in direct opposition to most professional learning programs' educational goals - programs that foster expertise in a given area.

I have yet to meet anyone in any Indigenous education communities who will claim to be an expert in their Indigenous-related knowledge. That is not to say that many people do not have expertise; instead, my statement is intended to point to the incredible respect and understanding of the boundless teachings that the universe has to offer. Seeing the world as a limitless teacher gives rise to great humility. In contrast, a worldview that imagines learning to be attained through neatly parcelled chunks - lessons, units, series, outcomes, courses, programs - produces all-knowing experts. I believe that the comparison as mentioned earlier highlights the jagged worldviews described by Leroy Little Bear (2000).

To elaborate further, participants in the learning series, along with all Indigenous education students who begin to see and understand the world differently, will not claim expertise in the Eurocentric sense of expert-knowledge: a narrowing down or narrowing in. Instead, Indigenous teachings recognize that observing, respecting, and caring for the world may lead to an opening up of possibilities and insights. The pedagogical awakenings most noted by the participants include learning on the land; ethical relationality (Donald, 2009); storytelling; Elder teachings; and listening. As Janelle said, "Learning is your responsibility and it often comes through listening." She also proffered, "We cannot do this work without trust and relationships." I believe that reconciliation is alive and that trans-systemic education is possible in spaces where Indigenous pedagogies and knowledges are being shared with generosity and received with grateful humility — truly touching the hearts and minds of learners.

\section{Confronting Truths, Narratives, and Silences (Mike Holden)}

In reading the transcripts, I was particularly struck by how much of what our participants shared reflects a desire to confront the truths, narratives, and silences that they encountered. I noticed how participants were troubled, for example, by the many ways silence had taken root in their schools. Sometimes this silence was literal: Sylvie shared a story of a school that chose (knowingly or not) to schedule their school spirit day on September 30, Orange Shirt Day. ${ }^{4}$ In

4 Orange Shirt Day is an act of recognition, reconciliation, and healing around Residential School experiences. The date in September is aligned with the time of year when Indigenous children were taken from their families, brought to Residential Schools, and often had their cultures literally stripped from them. The story grounding Orange Shirt Day is with regards to an Indigenous child, Phyllis Webstad, whose brand new orange shirt was among the items taken from her by the authorities (https://www.orangeshirtday.org). 
a photograph the school posted online, one child wore an orange shirt in a sea of school-spiritblue, but that act of resistance went unacknowledged.

For many of the participants, the silence embedded in or driven by Eurocentrism manifested as ignorance; several non-Indigenous participants recalled only recently learning about residential schools' history. Sylvie described it as a challenge of people "not really hearing." She continued, "Some people were completely oblivious to it and had no idea what I was talking about."

Writing in an American context, Caruthers (2007) describes a "soil of silence" (p. 303) that masks the social, educational, and cultural roots of injustice. Only when that soil is disturbed and confronted can teachers and students see the devastating consequences this silence has had. Paul captured this notion well when reflecting on his own journey:

[Being part of this work] allowed me the time and space to be reflective of my own role and privilege, and the challenges that other people have that I'm not aware of.... Like sure, I had heard about residential schools, and things like that ... but my knowledge of even just residential schools wasn't very deep. There wasn't anything during my academic work that was about intergenerational trauma. That's actually a fairly new term to me.

Paul's reflections resonated with my own experiences. I was born less than 30 minutes from the largest reserve in Canada and went to school with many Indigenous students. Despite that opportunity, I knew almost nothing about Indigenous peoples before attending university. Like many Canadians, I was steeped in silences that restricted these conversations to the past - almost always in the history classroom. We were told Indigenous people lived in longhouses, traded furs, and weren't terribly fond of railroads. "Civilizing influences" weren't problematized, and lasting challenges like intergenerational trauma were never mentioned. Amanda offered a promising story about this all-too-common issue:

What our students' knowledge is, and how they speak and understand Indigenous cultures and people, has changed massively in five years. At the beginning, Indigenous people were extinct. They only existed a long time ago, they're not around today.... And so even, you know, bringing people in from the community and sharing stories in the school, and going out on field trips, they get that Indigenous people are part of our community and they have strengths and they have their part of our past and our future. And so it's a change in the language they use, it's a change in their perspective and how they view the world.

By confronting those silences and growing with her students, Amanda creates a space where her students can learn from and alongside Indigenous perspectives.

Beyond silence, participants also recognized persistent, harmful narratives about Indigenous education and Indigenous students. One such narrative surrounded teachers and parents, 
challenging why Indigenous perspectives were being given attention at all. Cristina shared:

So many times I hear, "Can't they just get over it and move on?" And it just — it's like nails on a chalkboard to me. And it comes from people that truly have no understanding. How can you even say that when you have no base of knowledge? You can't just get over it and move on.... They don't know, children taken away, some were brought back, and then the community wouldn't allow the children back. All that trauma. Growing up not knowing how to care for your own child. No, you don't just move over, or move on and get over it. You don't. It takes time. Frustrating.

Coral expressed similar frustrations when she recalled a non-Indigenous parent who complained about a school sports event. The event encouraged Indigenous students to play and learn about their culture in a local setting. The parent wanted to know, "Why couldn't her son come?" Coral continued:

Actually, your son can come if he wants, but you need to understand that your son can go anywhere and do anything. [Indigenous] kids are not welcome [in the community]. And I'm serious about this. I have seen it firsthand in the community. I have a friend on Vancouver Island who got me to go to Walmart with her one day. And she said, "Stay back about 10 feet and watch what happens." Within minutes of us entering the store, we pretended we were apart, and there was a store detective behind her, watching her.

I felt especially drawn to Coral's story because of my own experiences learning about the prejudices Indigenous students and communities face that I never had to consider. In 2016, I was invited to visit one of the high schools we work with to learn about the work they were doing around social justice and environmental sustainability. I had never been on reserve before, and I was shocked by the number of people who felt the need to "warn me" ahead of the visit: to be careful, to tell me how I'd be entering "a different world," somewhere "like a third-world country."

While Canada continues to be criticized for the profound disparity between urban and reserve communities (United Nations, 2019), the warnings I received felt misplaced. I have visited that community five times since moving to Alberta, and I have always felt safe, welcomed, and privileged. That stands in sharp contrast to the stories those students have shared with me. As young Indigenous women, they are all too aware of missing and murdered Indigenous women and how that crisis manifests in their community. Like Coral's friend, they have shared stories of being watched by security staff every time they visit off-reserve malls. Their championship basketball team players - who should be excited about competing with schools from across the province - instead face reminders to travel in pairs, to avoid strangers, and talk about what to do "if they are taken." 
Again, I was drawn to what Kenneth and Coral shared as I reflected on my learning with the reserve high school students. When I come into that space, I wonder, am I the only one that notices that I am a White male representing a university? Am I actually welcome here, or am I imposing myself on these students and their teachers?

That sentiment of fear of making mistakes is powerful - as Cassidy shared, it is far easier not to engage, to stay away, so that we do not offend, impose, or recolonize. But as Coral and Kenneth point out, while we will make mistakes, that is part of the learning. That counternarrative of willingness to engage in the work despite its messiness appeared across the interviews. Amanda perhaps captured it best when she was asked how she saw herself as a leader in Indigenous learning: "I'm a learner in Indigenous learning....I've chosen to go and try to build relationships with people....and so you're building relationships, and those relationships, we're hoping, are reciprocal in different ways."

\section{Knowledge Production, Privilege and Solidarity (Mairi McDermott)}

As a White woman, I represent most educators in North American schools - regardless of student demographics (Sleeter, 2001). During my time as an English language arts teacher in a disinvested Brooklyn high school populated by youth and families who identified as African American, Caribbean, and Latinx, I became acutely aware of the need for more substantive representation of equity-seeking peoples and knowledges. As an outsider, however, I often wondered about my relationship with nondominant and marginalized knowledges. Rather than shying away from engaging different knowledges that are geopolitically located because of dangers around cultural appropriation, I felt (and still feel) that I had an ethical responsibility to find a way to disrupt Eurocentric concepts of what counts as knowledge and where knowledge resides (see, for example, Dei \& McDermott, 2019). These are some of the experiences that drew me into the present research on the ways that teachers with varied relationships to Indigenous knowledges integrate this knowledge into their practices. While we are at the early stages of institutionally mandated foci on Indigenous knowledges, I must admit that I am hopeful that we can move beyond integration and instead focus on disrupting, de-linking, and moving towards epistemic disobedience (Mignolo, 2002) as a way to re-organize and inscribe the possibilities for schools and society.

Much like many of the participants interviewed in this research, I waver between being hopeful about the willingness to name and mark coloniality through these government and institutional initiatives, and recognizing that the documents and policies themselves cannot do the work alone (Ahmed, 2012). Paula, who identifies as a non-Indigenous ally or co-conspirator shared this perspective: "I don't love that the move towards learning was, 'Oh, there's going to be some accountability in the teacher quality standards around First Nations, Métis, Inuit culture, so we better learn about it,' but whatever gets the ball rolling."

What resonated with me was that while she recognized the potential problem of what is propelling people's focus on engaging with Indigenous knowledges and ways of learning and being, strategically, we must take this moment to "get the ball rolling." Indeed, of the four participants who identified as Indigenous, three explicitly noted the importance of having the 
policy make their lifeworlds, histories, and experiences legible, even as they were on their paths of learning and seeing themselves differently.

Honouring that everyone is on their own learning path resonated in several ways. Both the Indigenous and non-Indigenous educators agree that we each have a role to play. From one perspective, Laura, an Indigenous educator, actively invites people into the work by making explicit what stories can be told and, more so, that non-Indigenous folks need to tell certain stories:

When I tell you a story, I'm trusting you to keep it alive, and you have to care for this. Like, you have to walk around with the story in your hands from now on. [...] And so, oh. Oh. Like they see themselves as part of and that it's important that they carry it carefully with love and grace. And it doesn't mean that you get to go tell, you know, the stories you've heard from other people. I'm just telling you [that] you can tell this story.

Laura doesn't ask the non-Indigenous educator to sort through what stories they can tell on their own; instead, she guides and allows them to see what stories they must tell. However, this level of explicit boundary marking cannot be expected from every educator who identifies as Indigenous. That proposition is problematic, placing the burden of decolonizing on Indigenous peoples. As Laura says at another point in the interview and Jennifer Markides also amplifies in her reflection: "Just because you're Indigenous doesn't mean you need to do Indigenous work."

This seemingly mundane statement re-orients us to the Eurocentric view of knowledge as geopolitically situated. The only universal knowledge is Eurocentric, objective, scientific, verifiable, and so on. In contrast, Others have local knowledges, and membership in the cultural group means you can speak for the entire group.

Being in a position of privilege, both due to my institutionally backed title and as an educated White woman, I am reminded by Paula that I must stand beside so that I can know when, where, and how to interrupt. Freire (1970) reminds me that "true solidarity with the oppressed means fighting at their side to transform the objective reality which has made them these "beings for another"' (p. 49). In her role as a non-Indigenous graduation coach, Paula lived this sense of solidarity. Importantly, she was recognized in the Indigenous community as an "ally" who can help to support the two worlds, Eurocentric and Indigenous, living together trans-systemically.

Yet, much of her discussion in the interview was around the struggles with getting other non-Indigenous colleagues on side, which she saw as part of her role as ally-bridge. This came with difficulties though, as she said: "And trying to negotiate how do you inform people of it and honour that it's new learning for some folks?" Her recognition that to function as an ally is exhausting, requiring the ability to "create that boundary for myself, to be able to say, like, I can help you unpack as far as I think you are able to in terms of your understanding and expectation of what my role is here," but this also perpetuated her privileged position. 
Paula would find ways to bridge the two knowledge systems by making connections between them. She used her position to speak to a particular audience, to help them bridge and make connections. For example, she talks about the difference between

[the] brain science behind trauma-informed practice and adverse childhood experiences and trauma awareness, and then the circle of courage, and using that sort of notion of balance. And if I could bridge those two worlds of, like, neuroscience and then Indigenous ways of knowing and understanding people got behind it.

Simultaneously, her privilege allowed her to step away when her well-being was affected, as reflected in her words: "And so I think of those that, like, don't get to step away, right."

This acknowledgement came with a stronger sense of responsibility because as she continued, she notes the ways in which who you are to your audience shapes the way your messages are interpreted: "So I say that knowing, like, I would like the messaging to be the same, but I also know that it can't be the same because of who is giving the message in front of class too."

Paul, a non-Indigenous educator, said that "what I learned was to question my own experience and my own perspective on things." Both Paul and Paula agreed on how important it was to resist the "expert" position hoisted upon images of the teacher (Britzman, 2003). Instead, they both worked to make themselves vulnerable as they shared their learnings, struggles, and mistakes. Many non-Indigenous educators saw their role as bridging and inviting others into the mess without the worry - of messing something up or saying something wrong - stopping them from trying. Often they saw their audience as other non-Indigenous educators, students, and community members, and a common approach was similar to Paula, above. She spoke the language she was familiar with, making connections to the Indigenous ways of knowing as an act of trans-systemic invitation.

\section{Conclusion}

As authors, researchers, and individuals, we each agree that everyone has a role to play in this trans-systemic work. We cannot ethically ask those oppressed, marginalized, and dehumanized in the ongoing colonial structures of Eurocentric-dominant culture to bear the burden of decolonization (Battiste, 2013a; Patel, 2016a). Furthermore, while social identity matters, we cannot assume that those who identify as Indigenous have decolonial mindsets because we have all been told the same social stories repeated through various institutions in society (Battiste, 2013a, 2013b; Shohat \& Stam, 2009; Smith, 2012). We believe, along with many other key scholar-activists, that schools and research — even though steeped in colonialism are necessary elements of the process of re-structuring their bases and promoting and educating broader societal changes (Battiste, 2013; Patel, 2016a; Smith, 2012). What we learned through the research, through listening to and with our research participants as they navigated the potential beyond-spaces opened in the historical moment of provincial educational policies, is how the trans-systemic requires multilayered approaches in various institutions (e.g., schools 
and research). We are furthermore reminded — and rejuvenated — that the emphasis of reimagining the mess has inherent and valuable potential for transformative possibilities in the processes of learning and unlearning.

Leroy Little Bear (2000) explains ideological differences between Eurocentric and Indigenous worldviews, notably between stability and flux, respectively. In Western culture, stability is valued such that the education system seeks to maintain, repeat, and improve upon successful models and experiences (e.g., best practices). In contrast, many Indigenous groups see the world as existing in a perpetual state of flux, recognizing continuous renewal cycles as the norm. While contrasts endure in these perspectives and we don't suggest conflating the two worldviews, this inquiry's framework is driven by our desire to immerse ourselves in the messiness of learning to view, work, and live differently while creating a trans-systemic space in schools and research.

As such, we return to Elder Clarence's guidance that reminds us to crawl before we walk. We have each felt that, while it is important to incorporate Indigenous knowledges into our current educational practices for the benefit of all students, we must resist the temptation to run straight into best practices and checklists for already over-extended teachers and leaders in our schools. Our research participants echo these sentiments. Incorporating Indigenous knowledges into existing educational policy, teaching, and leadership will take time. We are all at different stages on our learning paths, some requiring removing significant debris leftover from the Eurocentric marinade in which we are all steeped. It is our hope, however, that our collective voice in part one and individual narratives of reflection and vulnerability in part two invite others to join in the promise of doing and being in more relationally just and trans-systemic ways through our teaching, research, and learning practices (Donald, 2009; Ricoeur, 1990).

\section{About the Authors}

Mike Holden is a Doctoral student at Queen's University and served as the Youth Leadership Facilitator for the Werklund School of Education at the University of Calgary. His research interests include assessment, teacher education, and equity. His professional interests include enhancing how we prepare emerging teachers and developing stronger collaborative networks between teacher educators in Canada. Email: michael.holden@ucalgary.ca

Jennifer MacDonald is a Doctoral candidate in the Werklund School of Education. Emerging from experiences as an outdoor environmental educator, Jennifer's research focuses on holistic ways of knowing and the dynamic meaning-making that can arise through lived experiences with the land. She is also a sessional instructor of Indigenous Education. Email: jennifer. macdonald2@ucalgary.ca 
Mairi McDermott (corresponding author) is Assistant Professor and Chair in Curriculum and Learning at the Werklund School of Education, University of Calgary. Her research broadly queries what kinds of teaching and learning can push us beyond the existing habits and assumptions of colonial ways of knowing, being, and relating in schools and society. Email: mairi.mcdermott@ucalgary.ca

Jennifer Markides is an Eyes High Postdoctoral Fellow in the Werklund School of Education at the University of Calgary. She is Métis, and an Indigenous educator, researcher and activist. Her graduate research analyzed stories told by youth who transitioned from life-in-school during the 2013 Alberta floods through a holistic lens.

\section{References}

Abram, D. (1996). The spell of the sensuous: Perception and language in a more-than-human world. Pantheon Books.

Ahmed, S. (2012). On being included: Racism and diversity in institutional life. Duke University Press. Alberta Education (2018). First Nations, Metis and Inuit Education: Education for reconciliation. Retrieved from https://education.alberta.ca/first-nations-métis-and-inuit-education/ education-for-reconciliation/everyone/overview/

Alberta Education (2019a). Leadership Quality Standard. Retrieved from https://education.alberta. ca/media/3739621/standardsdoc-lqs-_fa-web-2018-01-17.pdf

Alberta Education. (2019b). Teaching Quality Standard. Retrieved from https:/education.alberta.ca/ media/3739620/standardsdoc-tqs-_fa-web-2018-01-17.pdf

Archibald, J.-A. (2008). Indigenous storywork: Educating the heart, mind, body and spirit. UBC Press.

Battiste, M. (2013a). Decolonizing education: Nurturing the learning spirit. UBC Press.

Battiste, M. (2013b). You can't be the doctor if you're the disease: Eurocentrism and Indigenous renaissance. CAUT Distinguished Academic Lecture, April 26, 2013.

Britzman, D. P. (2003). Practice makes practice: A critical study of learning to teach (revised). SUNY Press.

Caruthers, L. E. (2007). The soil of silence: Deconstructing socio-cultural and historical processes that have influenced schooling for First Nations people and African Americans. American Educational History Journal, 34(2), 303-313.

Dei, G. J. S., \& McDermott, M. (Eds.) (2019). Centering African proverbs, Indigenous folktales, and cultural stories in curriculum: Units and lesson plans for inclusive education. Canadian Scholars Press.

Donald, D. (2009). Forts, curriculum, and Indigenous métissage: Imagining decolonization of Aboriginal-Canadian relations in educational contexts. First Nations Perspectives, 2(1), 1-24. 
Donald, D., Glanfield, F., \& Sterenberg, G. (2012). Living ethically within conflicts of colonial authority and relationality. Journal of the Canadian Association for Curriculum Studies, 10(1), 53-76.

Four Arrows (Wahinkpe Topa), aka Jacobs, D. T. (2008). The authentic dissertation: Alternative ways of knowing, research, and representation. Routledge.

Freire, P. (1970). Pedagogy of the oppressed. Continuum Publishing Corporation.

Government of Canada. (2020). Indian Act (RSC, 1985, c. I-5). Retrieved from https://laws-lois. justice.gc.ca/eng/acts/I-5/

Graveline, F. J. (2000). Circle as methodology: Enacting an Aboriginal paradigm. International Journal of Qualitative Studies in Education, 13(4), 361-370.

hooks, b. (1994). Teaching to transgress: Education as the practice of freedom. Routledge.

Kapyrka, J. \& Dockstator, M. (2012). Indigenous knowledges and western knowledges in environmental education: Acknowledging the tensions for the benefits of a "two-worlds" approach. Canadian Journal of Environmental Education, 17, 97-112.

Kovach, M. (2009). Indigenous methodologies: Characteristics, conversations, and contexts. University of Toronto.

Little Bear, L. (2000). Jagged worldviews colliding. In M. Battiste (Ed.), Reclaiming Indigenous voice and vision (pp. 77-85). UBC Press.

MacDonald, J. \& Markides, J. (2018). Called to action: Dialogue around praxis for reconciliation. In L. Daniels, S. Deer, D. Donald, B. Low, and D. Wiseman (Eds.). Taking up the Calls to Action of the TRC in Teacher Education [Special Issue]. McGill Journal of Education, 53(2), 213-232.

MacDonald, J., \& Markides, J. (2019). Duoethnography for reconciliation: Learning through conversations. Alberta Journal of Educational Research, 65(2), 1-16.

Mann, B. A. (2003). Native Americans, archaeologists, and the mounds. Peter Lang.

McDermott, M. (2020). On what autoethnography did in a study on student voice pedagogies: A mapping of returns. The Qualitative Report, 25(2), 347-358. Retrieved from https:// nsuworks.nova.edu/tqr/vol25/iss $2 / 5$

Mignolo, W. (2002). The geopolitics of knowledge and the colonial difference. The South Atlantic Quarterly, 101(1), 57-96.

Miles, M. B., Huberman, A. M., \& Saldaña, J. (2014). Qualitative data analysis: A methods sourcebook $\left(3^{\text {rd }}\right.$ ed.). Sage.

Patel, L (2016a). Decolonizing educational research: From ownership to answerability. Routledge.

Patel, L. (2016b). Pedagogies of resistance and survivance: Learning as marronage. Equity \& Excellence in Education, 49(4), 397-401.

Regan, P. (2010). Unsettling the settler within: Indian residential schools, truth telling, and reconciliation in Canada. UBC Press.

Ricoeur, (1990). Oneself as another (K. Blamey, Trans.). University of Chicago Press.

Sandoval, C. (2000). Methodology of the oppressed. University of Minnesota Press.

Sensoy, O. \& DiAngelo, R. (2012). Is everyone really equal? An introduction to key concepts in social justice education. Teachers College Press.

Sheridan, J. \& Longboat, D. R. "He Clears the Sky" (2006). The Haudenosaunee imagination and the ecology of the sacred. Space and Culture, 9(4), 365-381. 
Shohat, E. \& Stam, R. (2009). What is Eurocentrism? In A. H. Itwaru (ed.) The white supremacist state: Eurocentrism, imperialism, colonialism, racism, (pp. 137-156). The Other Eye.

Sleeter, C. E. (2001). Preparing teachers for culturally diverse schools: Research and the overwhelming presence of Whiteness. Journal of Teacher Education, 52(2), 94-106.

Smith, L. T. (2012). Decolonizing methodologies: Research and Indigenous peoples (2 $\left.{ }^{\text {nd }} \mathrm{ed}.\right)$. Zed Books.

St. Denis, V. (2007). Aboriginal education and anti-racist education: Building alliances across cultural and racial identity. Canadian Journal of Education, 30(4), 1068-1092.

Truth and Reconciliation Commission of Canada. (2015). Truth and reconciliation commission of Canada: Calls to action. Winnipeg: Truth and Reconciliation Commission of Canada. Retrieved from http://trc.ca/assets/pdf/Calls_to_Action_English2.pdf

United Nations General Assembly. (2019). Adequate housing as a component of the right to an adequate standard of living, and the right to non-discrimination in this context (A/74/183). Retrieved from https://www.undocs.org/A/74/183

wa Thiong'o, N. (1986). Decolonizing the mind: The politics of language in African literature. James Currey.

Wagamese, R. (2016). Embers: One Ojibway's meditations. Douglas \& McIntyre.

Wynter, S. (2003). Unsettling the coloniality of being/power/truth/freedom: Towards the human, after man, its overrepresentation - An argument. The New Centennial Review, 3(3), 257-37. 